\title{
Water vapour and carbon dioxide decrease nitric oxide readings
}

\author{
Th.W. van der Mark, E. Kort, R.J. Meijer, D.S. Postma, G.H. Koëter
}

Water vapour and carbon dioxide decrease nitric oxide readings. Th.W. van der Mark, E. Kort, R.J. Meijer, D.S. Postma, G.H. Koëter. COERS Journals Ltd 1997.

ABSTRACT: Measurement of nitric oxide levels in exhaled air is commonly performed using a chemiluminescence detector. However, water vapour and carbon dioxide affect the chemiluminescence process. The influence of these gases at the concentrations present in exhaled air, has not yet been studied.

For this in vitro study, mixtures of 50, 100 and 200 parts per billion (ppb) NO in air were prepared and fed into the NO analyser either directly or bubbled through water. Mixtures with $\mathrm{CO}_{2}$ were prepared by adding $0-10 \% \mathrm{CO}_{2}$ to the diluent air.

We found a significant decrease in NO readings in the water-saturated samples compared to the dry gas $(\mathbf{p}<\mathbf{0 . 0 0 1})$, strongly dependent on the partial pressure of water. NO levels in exhaled air (mean $10 \pm 2 \mathrm{ppb}$ ) showed a decrease of $17 \pm 3 \%$ when waer vapour was not absorbed. From the experiments with $\mathrm{CO}_{2}$ we found a decrease in $\mathrm{NO}$ reading of $1.04 \pm 0.07 \%$ per volume $\mathrm{CO}_{2}(\%)$.

Presence of water vapour, thus, leads to a systematic underestimation of NO levels. Insertion of a water absorber might, therefore, be advantageous. The influence of $\mathrm{CO}_{2}$ concentrations in the normal respiratory range is negligible. With high expiratory $\mathrm{CO}_{2}$ levels as applied in permissive hypercapnia, the effects may be substantial.

Eur Respir J 1997; 10: 2120-2123.
Correspondence: Th.W. van der Mark

Dept of Pulmonology

University Hospital Groningen

P.O. Box 30.001

9700 RB Groningen

The Netherlands

Keywords: Carbon dioxide

exhaled air

nitric oxide

water vapour

Received: December 101996

Accepted after revision May 271997
Measurement of nitric oxide levels in exhaled air is commonly performed by a chemiluminescence detector, in which NO reacts with $\mathrm{O}_{3}$ to form high energetic $\mathrm{NO}_{2} *$. Only a small fraction (typically less than $1 \%$ ) of the energy carried by the $\mathrm{NO}_{2}{ }^{*}$ molecules is dissipated by emission of photons. The major part is dissipated by interaction with other molecules in the reaction chamber. The latter process is called third body quenching, and is dependent on sample composition and reaction chamber pressure. The effect of variations in sample composition and reaction chamber pressure follows the well-known Stern-Volmer relation [1, 2]:

$$
F=\frac{P \mathrm{NO}_{2}}{B\left(1+\sum \text { ai } P \mathrm{i}\right)}
$$

where $F$ is the emission signal, $B$ is a proportionality constant which is instrument dependent, $\mathrm{PNO}_{2}$ is the partial pressure of the $\mathrm{NO}_{2}$ formed (proportional to the $\mathrm{NO}$ concentration in the sample gas), $P \mathrm{i}$ is the partial pressure of the i-th component in the sample gas, and ai is the corresponding quenching constant. The relative quenching $(R)$ can then be defined as the ratio of the NO signal in the presence of the quenching gas and the NO signal without that gas. From Equation 1 it follows that the relative quenching for a single gas can be given as [3]:

$$
R=\frac{1}{1+\mathrm{b} \cdot P}
$$

in which the constant $\mathrm{b}$ comprises both instrumental properties and the quenching constant of the gas at the partial pressure $(P)$ in question.

Thus, gas composition influences the chemiluminescence signal. Water vapour and $\mathrm{CO}_{2}$ have quenching constants considerably exceeding those of $\mathrm{N}_{2}$ and $\mathrm{O}_{2}$ [3], and may therefore decrease the NO signal. This is a well-known phenomenon in the analysis of combustion engine exhaust gases [2-4], where NO detector efficiency may decrease to $60 \%$ [3]. However, the composition of exhaust gases is quite different from exhaled air. The present study was undertaken to investigate whether water vapour and $\mathrm{CO}_{2}$, at the concentrations present in exhaled air, have a measurable influence on NO readings.

\section{Methods}

Mixtures of 50, 100 and 200 parts per billion (ppb) $\mathrm{NO}$ in air were prepared by diluting a 100 parts per million (ppm) $\mathrm{NO}$ in $\mathrm{N}_{2}$ mixture from a certified bottle with NO-free air $(<2 \mathrm{ppb} \mathrm{NO})$ by precision mass flow controllers (accuracy 0.1\%, Bronkhorst Hi-Tec BV, Ruurlo, The Netherlands). Tubing, fittings and valves were made from polytetrafluoroethylene (PTFE) and stainless steel. The diluted gas was fed into a $50 \mathrm{~L}$ plastic bag. The whole system (bag and tubing) was tested for leaks and absorption of NO by filling the bag with a $100 \mathrm{ppb}$ NO 


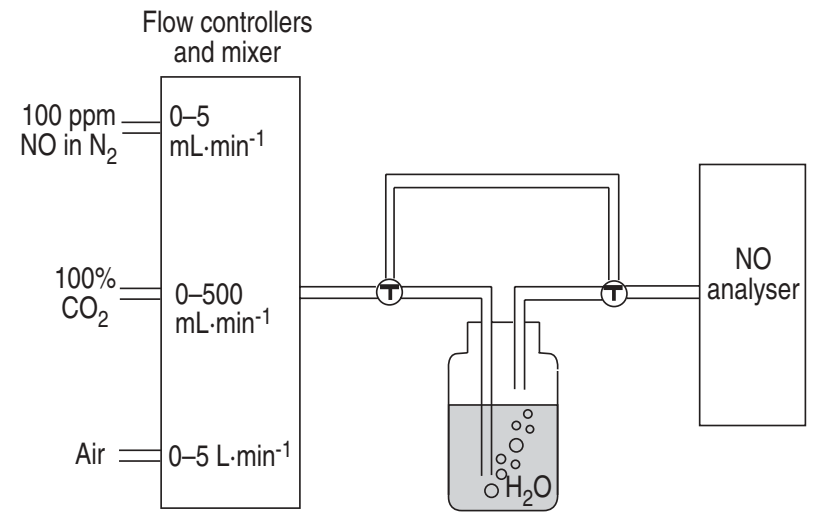

Fig. 1. - Schematic drawing of the connections of the flow controllers and mixer to the NO analyser. Each flow controller can be adjusted in steps of $1 \%$ of its entire range. ppm: parts per million.

mixture and analysing it after $1 \mathrm{~h}$. We found no measurable change in NO concentration.

Samples from the mixing bag were passed into the measuring port of the NO analyser (CLD 700AL, Ecophysics, Basel, Switzerland), either directly or bubbled through a flask of distilled water of $23^{\circ} \mathrm{C}$ (fig. 1). The lower detectable limit of the analyser was $1 \mathrm{ppb}$ with a resolution of $\pm 1 \mathrm{ppb}$. The sampling flow was 600 $\mathrm{mL} \cdot \mathrm{min}^{-1}$ and the response time, including lag and rise time was $<7 \mathrm{~s}$. The linearity was $\pm 1 \%$ full scale. The analyser was equipped with a separate channel for $\mathrm{NO}_{\mathrm{x}}$ measurements (NO plus higher oxides of nitrogen).

Consecutive measurements were performed with dry and wet gas in triplicate for each of the three NO concentrations. The gas from the diluting system was also connected directly to the separate calibration port present in the analyser, in order to perform calibration procedures according to the instructions of the manufacturer. Calibration was checked in this way before and after each measurement. A second set of measurements was made using an input concentration of $200 \mathrm{ppb}$ and water temperatures of 23 and $38^{\circ} \mathrm{C}$. Thereafter, the wet gas was passed through a cold trap, cooled by a Peltier element to $-7^{\circ} \mathrm{C}$. Mixtures with $\mathrm{CO}_{2}$ were prepared by adding $0-10 \% \mathrm{CO}_{2}$ to the diluent air and fed into the analyser, bypassing the water flask.

Measurements in normal subjects were made using the tidal breathing method described by ScHILLING et al. [5]. Briefly, subjects breathed air containing $<2 \mathrm{ppb} \mathrm{NO}$ via a two-way breathing valve. Expired air was collected in a bag for 5 min and subsequently analysed.

\section{Results}

We found a significant decrease in NO readings of $14.0 \pm 0.7 \%$ in the water-saturated samples compared to the dry gas (fig. 2), the slope of the calibration line for wet gas being $0.860 \pm 0.007(\mathrm{p}<0.001,95 \%$ confidence interval (95\% CI) 0.838-0.882), at a partial pressure of water vapour $\left(\mathrm{PH}_{2} \mathrm{O}\right)$ of $2.81 \mathrm{kPa}$ (water temperature $23^{\circ} \mathrm{C}$ ). At a $\mathrm{PH}_{2} \mathrm{O}$ of $6.63 \mathrm{kPa}$ (temperature $38^{\circ} \mathrm{C}$ ), a decrease of $24.5 \pm 1.5 \%$ was observed, whereas no decrease was apparent at a $\mathrm{PH}_{2} \mathrm{O}$ of $0.34 \mathrm{kPa}$ (temperature $-7^{\circ} \mathrm{C}$ ). The raw values must be corrected for the volume of the water vapour introduced by the bubbling through water, the corrected values being $12.0 \pm 0.7 \%\left(23^{\circ} \mathrm{C}\right)$ and $19.2 \pm$
$1.5 \%\left(38^{\circ} \mathrm{C}\right)$. The relative quenching $(R)$ for water was then calculated by fitting Equation 2 to the data points (fig. 3). The value of $b$ for water $\left(\mathrm{bH}_{2} \mathrm{O}\right)$ was $0.038 \pm 0.004$ $\mathrm{kPa}^{-1}$.

From the experiments with $\mathrm{CO}_{2}$, we found a decrease in $\mathrm{NO}$ reading of $1.04 \pm 0.07 \%$ per volume $\mathrm{CO}_{2}(\%)$ (fig. 4) $(\mathrm{p}<0.005)$. The value of $\mathrm{b}$ for $\mathrm{CO}_{2}\left(\mathrm{bCO}_{2}\right)($ Equation 2) was calculated as $0.011 \pm 0.001 \mathrm{kPa}^{-1}$, taking into account the barometric pressure $(102.5 \mathrm{kPa})$ at the time of the measurements.

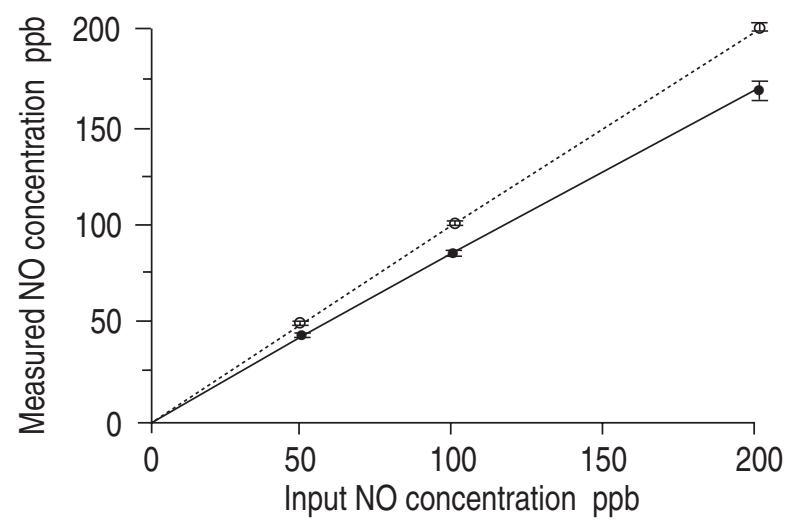

Fig. 2. - Calibration lines for dry and wet gas (saturated with water vapour at $23^{\circ} \mathrm{C}$ ). ……….... dry gas; - : wet gas. The line for dry gas is the same as the line of identity.

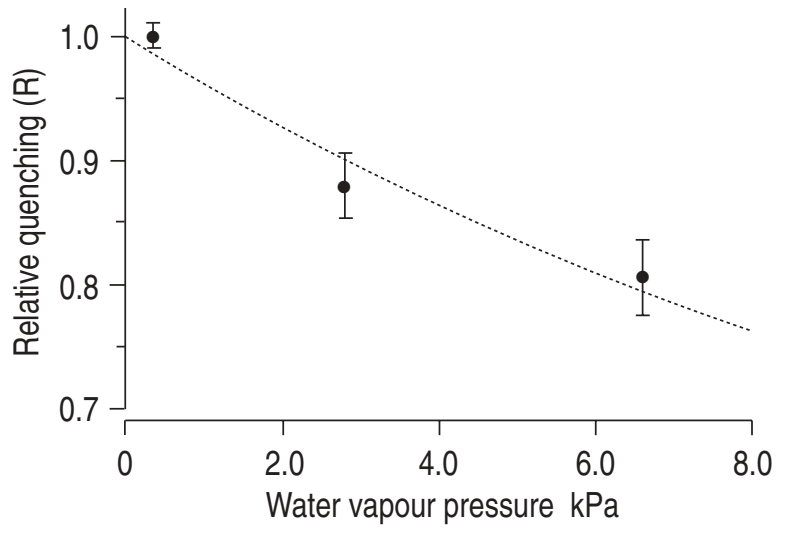

Fig. 3. - Relative quenching as function of the partial pressure of water vapour. The line is the best fit of equation 2 (see text) to the data points.

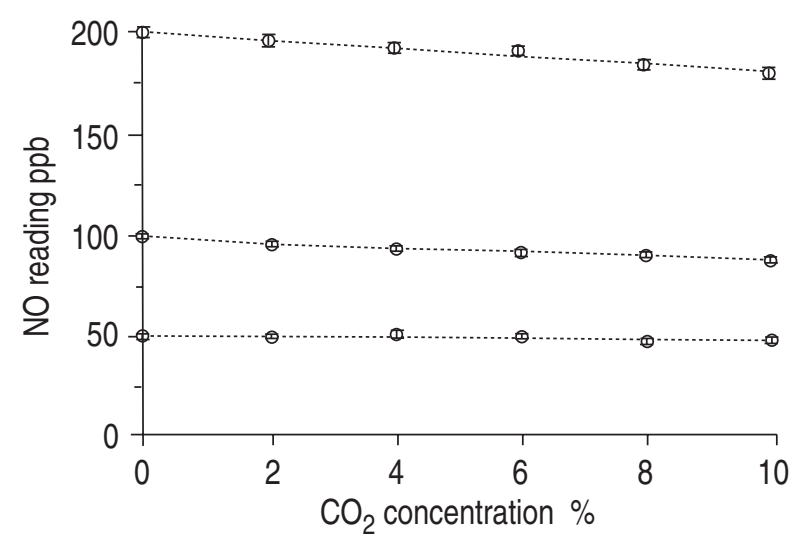

Fig. 4. - Decrease of NO readings with increasing $\mathrm{CO}_{2}$ concentration at fixed NO concentrations of 50, 100 and 200 parts per billion (ppb). 
During the experiments, the readings in the $\mathrm{NO}_{\mathrm{x}}$ channel were continuously monitored. All readings were concordant with the values obtained from the NO channel, indicating that no additional $\mathrm{NO}_{2}$ was formed.

In addition, we measured NO levels in exhaled air of three normal subjects (mean $10 \pm 2 \mathrm{ppb}$ ) with and without a conventional $\mathrm{CaCl}_{2}$ water absorber in the tubing to the analyser. The NO reading without absorber was $8.3 \pm 2 \mathrm{ppb}, 17 \pm 3 \%$ lower than with the water absorber.

In the course of the experiments we observed that prolonged sampling of wet gas resulted in an increased time for the analyser to reach the initial stable calibration values (from $5 \mathrm{~min}$ initially to $20 \mathrm{~min}$ after performing all the experiments).

\section{Discussion}

We found a distinct decrease in $\mathrm{NO}$ readings due to the presence of water vapour and $\mathrm{CO}_{2}$, the former having a substantial influence when measuring NO concentration in exhaled air.

According to the equations given above, the partial pressures of the components of the sample gas determine the amount of quenching. By use of Equation 2 and the values found for the constants $\mathrm{bH}_{2} \mathrm{O}$ and $\mathrm{bCO}_{2}$, it is possible to calculate the relative quenching, and thereby the decrease in NO signal, for every partial pressure of these gases. The result is independent of the applied NO concentrations, since chemiluminescence detectors are known to be linear over several orders of magnitude [6].

It can be argued that the decrease of NO signal is partly caused by the reaction of NO with water. However, the reactions producing nitrous acid at these NO concentrations are very slow, as is the reaction with dissolved oxygen [7]. Moreover, we observed complete recovery of the NO signal after leading a wet gas sample through a cold trap. TidonA et al. [3] performed similar experiments at a much higher NO concentration (92 ppm) and found no measurable absorption by water.

The values of relative quenching efficiency, in molar fraction, for $\mathrm{H}_{2} \mathrm{O}$ and $\mathrm{CO}_{2}$ reported elsewhere [3], were about half the values found in the present study. These investigators used an analyser operating with a reaction chamber pressure of $1.3 \mathrm{kPa}$, while our analyser had a reaction chamber pressure of $5.2 \mathrm{kPa}$. Since low pressure tends to reduce quenching, we would expect the differences between the values reported in the present study and that of Tidona et al. [3] to result from the difference in analyser. The ratio of the quenching coefficients of $\mathrm{H}_{2} \mathrm{O}$ and $\mathrm{CO}_{2}$ found in the present study, is in good agreement with values reported previously [3, 4].

The influence of $\mathrm{CO}_{2}$ is limited. A variation of $2 \%$ $\mathrm{CO}_{2}$ in the expired air (e.g. the difference between mixed expired and end-tidal $\mathrm{CO}_{2}$ concentration) would lead to a variation of $0.4 \mathrm{ppb}$ at an average NO concentration of $20 \mathrm{ppb}$. This is below the detection limit. However, when using much higher NO concentrations, as applied in administering exogenous NO to patients with adult respiratory distress syndrome (ARDS), the effect of $\mathrm{CO}_{2}$ could be substantial. This is even more so during ventilation of patients with permissive hypercapnia [8, 9]. For instance, at 2,000 ppb NO, a sample wet gas of $34^{\circ} \mathrm{C}$ and a $\mathrm{CO}_{2}$ concentration of $10 \%$ would give a reading of 1,522 ppb, as calculated from Equation 1, using the observed values of $\mathrm{bH}_{2} \mathrm{O}$ and $\mathrm{bCO}_{2}$. In these cases it would be advantageous to remove both water and $\mathrm{CO}_{2}$ prior to measurement.

The results obtained when measuring NO levels in exhaled air are in concordance with our in vitro data. Assuming a temperature of $34^{\circ} \mathrm{C}$ in the exhaled air [10] $\left(\mathrm{PH}_{2} \mathrm{O}=5.32 \mathrm{kPa}\right)$, the corresponding decrease in $\mathrm{NO}$ reading was calculated as $16.8 \%$, compared to the experimental value of $17.0 \pm 3 \%$.

Water vapour may have another effect on analyser performance. Due to the use of stainless steel capillary tubes inside the analyser and the strong polar character of the water molecule, water can be adsorbed at the inside surface of the tubing. When switching back to dry gas, some time will be needed to remove all the adsorbed water.

The decrease in NO readings in water-saturated samples may be an important source of variation. Since the partial pressure of saturated water vapour increases considerably with temperature in the physiological range (more than twofold [11]), and the partial $\mathrm{H}_{2} \mathrm{O}$ pressure is the main determinant of the quenching effect, the temperature of the exhaled air determines the decrease in NO reading. This temperature depends on the means of sampling the exhaled air: directly at the mouth, or from a collection bag. Also, diameter and length of tubing are important. When the exhaled air temperature varies between $23^{\circ} \mathrm{C}\left(\mathrm{PH}_{2} \mathrm{O}=2.81 \mathrm{kPa}\right)$ and $34^{\circ} \mathrm{C}\left(\mathrm{PH}_{2} \mathrm{O}=5.32\right.$ $\mathrm{kPa}$ ) this would lead to decreases in $\mathrm{NO}$ readings of $14-27 \%$, i.e. $2.8-5.3 \mathrm{ppb}$, at an average NO concentration of $20 \mathrm{ppb}$. These figures are of the same order of magnitude as, for instance, the differences in NO concentration between mild asthmatics and normal subjects [12].

It is therefore advisable to use a water absorber in the tubing leading to the $\mathrm{NO}$ analyser. Our observation that prolonged sampling of wet gas may reduce analyser performance is an additional reason for such an absorber.

\section{References}

1. Stern O, Volmer M. Ueber die Abklingzeit der Fluoreszenz. Physik Zeitschr 1919; 20: 183-187.

2. Zabielski MF, Seery DJ, Dodge LG. Influence of mass transport and quenching on nitric oxide chemiluminescent analysis. Environ Sci Technol 1984; 18: 88-92.

3. Tidona RJ, Nizami AA, Cernansky NP. Reducing interference effects in the chemiluminescent measurement of nitric oxides from combustion systems. J Air Pollution Control Assoc 1988; 38: 806-811.

4. Campbell NT, Beres GA, Blasko TJ, Groth RH. Effect of water and carbon dioxide in chemiluminescent measurement of oxides of nitrogen. J Air Pollution Control Assoc 1982; 32: 533-535.

5. Schilling J, Holzer P, Guggenbach M, Gyurech D, Marathia K, Geroulas S. Reduced endogenous nitric oxide in the exhaled air of smokers and hypertensives. Eur Respir J 1994; 7: 467-471.

6. Seitz WR, Neary MP. Chemiluminescence and bioluminescence analysis. In: Hercules DM, ed. Contemporary Topics in Analytical and Clinical Chemistry. New York, Plenum Press, 1977, p. 58. 
7. Austin AT. The chemistry of the higher oxides of nitrogen as related to the manufacture, storage and administration of nitrous oxide. Br J Anaesth 1967; 39: 345350.

8. Puybasset L, Stewart T, Rouby JJ, et al. Inhaled nitric oxide reverses the increase in pulmonary vascular resistance induced by permissive hypercapnia in patients with acute respiratory distress syndrome. Anesthesiology 1994; 80: 1254-1267.

9. Levy B, Bollaert PE, Bauer P, Nace L, Audibert G, Larcan A. Therapeutic optimization including inhaled nitric oxide in adult respiratory distress syndrome in a polyvalent intensive care unit. J Trauma 1995; 38: 370-374.

10. Quanjer PH, Tammeling GJ, Cotes JE, Pedersen OF, Peslin R, Yernault JC. Lung volumes and forced expiratory flow. Eur Respir J 1993; 6 (Suppl. 16): 5-40.

11. Weast RC, Selby SM, eds. Handbook of Chemistry and Physics, 48th Edn. Cleveland, The Chemical Rubber Company, 1967; p. D-110.

12. Garnier P, Fajac I, Dessanges JF, Dall'Ava-Santucci J, Lockhart A, Dinh-Xuan AT. Exhaled nitric oxide during acute changes of airway calibre in asthma. Eur Respir J 1996; 9: 1134-1138. 